INVESTIGACIÓN/RESEARCH

\title{
COMPARATIVA DE CONTENIDOS ENOTURÍSTICOS EN LA WEB 2.0
}

Mónica Matellanes-Lazo': Universidad Europea Miguel de Cervantes de Valladolid, España.

mmatellanes@uemc.es

\section{RESUMEN}

El uso de Internet irrumpe en un momento importante del desarrollo del enoturismo en varias zonas de la geografía española y, es fundamental conocer y dominar la utilización de los elementos de este nuevo medio para impactar y comunicar de un modo eficaz los planes estratégicos de gestión del enoturismo hacia los diferentes públicos. Para conocer cuáles son los factores clave en el desarrollo de contenidos Web hacia estos clientes, este artículo de investigación utiliza un cuestionario comparativodescriptivo en 2011 de la gestión de las principales páginas Web del enoturismo en dos conocidas Denominaciones de Origen españolas: la D.O.C. La Rioja y la D.O. Ribera del Duero. De esta forma, se podrán analizar y reflexionar las diferentes técnicas de comunicación que aplican cada una de estas Denominaciones de Origen para conseguir más turistas y por tanto, beneficios económicos. Se pretende conocer qué tipo de contenidos son más atractivos e impactan mejor sobre el público objetivo, así como averiguar qué Denominación de Origen tiene mejor Imagen Corporativa. Finalmente se determinó por los resultados obtenidos que no existe una cohesión e integración de los contenidos de Enoturismo en las páginas Web del sector de la D.O. Ribera del Duero frente a las páginas Web del mismo sector en La Rioja, teniendo mejor imagen corporativa las páginas de esta última región vitivinícola.

PALABRAS CLAVE: Enoturismo - Internet - D.O. Ribera del Duero - D.O.C. La Rioja - Marketing

\footnotetext{
${ }^{1}$ Autor correspondiente:

Mónica Matellanes-Lazo: Profesora Doctora Adjunta de la Universidad Europea Miguel de Cervantes de Valladolid (España). Experta en Marketing y Comunicación del Enoturismo.

Correo: mmatellanes@uemc.es
} 


\title{
COMPARATIVE OF ENOLOGICAL-TOURISM CONTENT IN WEB 2.0
}

\begin{abstract}
The use of the internet bursts in a key moment for the enological tourism development in several regions of Spain and, it is essential to get to know and control the use of this new channel's elements to communicate in an efficient way the strategical plans of enological tourism management towards different audiences. This research uses a comparative questionnaire in 2011 about the management between the main enological-tourism websites of two important Origen Denomination: D.O.C. La Rioja and D.O. Ribera del Duero. Like that, we'll be able to analyze and reflect about different communication strategies which use every wine region to obtain more tourists and economic benefits. It's important to know what type of information is more attractive and shock publics better and find out what Origen Denomination has the best corporate image. At last we obtained that not exist union about enologicaltourism content in Webs of D.O. Ribera del Duero opposite Webs in D.O.C. La Rioja, with a better corporate image this last wine region.
\end{abstract}

KEY WORDS: Enological-tourism - Internet - D.O. Ribera del Duero - D.O.C. La Rioja - Marketing

\section{INTRODUCCIÓN}

Gracias a la creación de un Website (sitio Web), una empresa puede mantener su presencia directa en Internet y ofrecer información sobre sus productos y servicios.

Una aplicación muy interesante son los catálogos electrónicos, que además de suponer un ahorro para la empresa, permiten estar siempre actualizados. De este modo, también se pone a disposición del usuario información detallada sobre el producto y el cliente puede decidir la información que desea conocer sobre los productos de forma específica (Mayordomo, 2002a:124).

Esta aplicación comentada por Mayordomo (2002b: 127) determina lo que muchas empresas bodegueras y vitivinícolas están haciendo a través de la Web. La información sobre la bodega, el entorno, las fichas de los vinos, la elaboración y las novedades sobre las visitas y actos en bodega, se muestran a través de catálogos electrónicos o archivos en formato pdf que el usuario puede descargar perfectamente en su ordenador.

Para lograr el éxito en Internet, no es suficiente tener una Web muy bien diseñada, atractiva y con buenos contenidos de información. Es casi igual de importante darla a conocer y así generar audiencia y fidelizar a los visitantes. Y aún más importante, resulta este último punto si se tiene en cuenta la velocidad con la que proliferan las páginas Web (Pérez, 2000:12). 
Este nuevo medio publicitario de mayor tecnología permite determinar cuántas personas han accedido a una página $W e b, y$, por tanto, han visualizado el anuncio que se ha insertado en la misma. [...] Este medio permite llevar a cabo una segmentación bastante precisa del público objetivo de una campaña publicitaria, de tal forma que sólo se mostrará el anuncio a aquellos visitantes de la página Web que se ajusten al perfil deseado por el anunciante (Gómez, 2006: 81).

Y, por último, pero no menos importante, este medio posee una característica muy útil para la empresa. Esto es, Internet puede proporcionar datos exactos a tiempo real sobre resultados que se obtienen en una campaña publicitaria, así, si los resultados no cumplieran los objetivos buscados, podrían establecerse medidas para corregir el error y que mejorasen la respuesta del tipo de publicidad. Una opción que es impensable en otros medios de comunicación (Bachs et al., 2002: 45).

Internet es un medio interactivo donde el visitante elige qué quiere ver y a dónde dirigirse sobre las diferentes opciones que se le presentan en la pantalla. Por esta razón, el sitio Web debe ser sencillo y fácil de navegar, y permitir al usuario que llegue rápidamente a la información deseada sin necesidad de buscar demasiado. Si para el visitante no resulta atractiva ni cómoda la Web que visita la abandonará y acudirá a otra (Mayordomo, 2002c: 77).

Como medio de comunicación, Internet, permite el uso de tecnologías multimedia que revoluciona la manera de tratar la información y comunicarla. Esto se logra a la vez que también se consigue entretener al usuario. Se puede personalizar la visita, permitir al usuario la descarga de videos promocionales y otros muchos recursos que el visitante encontrará de mayor o menor utilidad pero que deben estar disponibles (Mayordomo, 2002d: 78).

También resulta un acierto los enlaces que funcionan como hipervínculos y así invitan al visitante que de una página Web concreta se visite otra relacionada con la misma. Esto permite continuar la búsqueda de información y contenidos más concretos sobre el tema en el que se esté interesado.

Por último, como se ha visto en líneas anteriores, es importante que el sitio Web ocupe un lugar destacado en los buscadores de Internet con mayor uso. El sitio Web es prácticamente el medio más importante de la empresa en Internet pues sirve a su vez de soporte para las demás herramientas de comunicación y marketing (Janal, 2000: 128).

Sin duda alguna, en la actualidad ninguna otra tecnología de información impacta tanto en el sector turismo como lo hace Internet, el cual ha cambiado los esquemas de comercio y de competencia mundiales. Mediante su uso, poco a poco se está cambiando a una economía que funciona las 24 horas del día los 365 días del año y en cualquier lugar del mundo (Fleming, 2000: 26). 
Una buena Web turística provista de una red de enlaces relacionados con el destino, enriquece el interés de un posible cliente.

Cuando un turista se interesa por un destino y decide recurrir a Internet para informarse acudirá a los principales buscadores. Es importante que ahí se sitúe la Web de la empresa en los primeros puestos, aumentando así las posibilidades de ser seleccionada.

Alonso $^{2}$ (2009), comenta que en un principio la empresa Rutas de Vino comenzó con un móvil y un portátil con conexión a Internet. A partir de entonces, generando los primeros negocios, bases de datos de clientes y proveedores, contactos con principales clientes y agencias, la infraestructura de Rutas de Vino mejoró con la creación de una oficina y dos puestos de trabajo a finales del año 2006. Hoy día, Cristina Alonso es de la opinión que gracias al sitio Web de su empresa y de este medio, ha podido trabajar con clientes desde cualquier rincón del mundo, facilitando el ahorro de desplazamientos y tiempo, pero siendo eficientes.

Uno de los principales objetivos de las páginas Web dedicadas al sector turístico es facilitar la información necesaria para los potenciales visitantes $y$, por lo tanto, posibles clientes. Es importante que esta información se muestre de manera organizada, atractiva y que resulte de fácil acceso. Esta puede ser la razón de la elección del visitante por encima de otro sitio Web (Mazarrasa, 1994: 67).

El turismo se ha consolidado como una de las empresas que se ha desarrollado con mayor éxito en Internet. En los últimos años ha aumentado el número de usuarios que utilizan este medio para realizar la compra de algún servicio turístico como boletos de avión o servicios de hospedaje.

Para mostrar la importancia de este tipo de comercio, se debe hacer referencia a las declaraciones de Trigueros 3 , Directora de Comunicación de Turismo de La Rioja. Por otro lado, Trigueros comenta que tanto las reservas como el pago de las mismas, se realizan en más de un $70 \%$ por Internet.

Esto refleja la importancia del turismo en España y cómo la aplicación de Internet en los viajes crece y ocupa un lugar preferente.

En este aspecto, hay que entender varios procesos y cambios que se han producido en el sector de la comunicación si se explica desde su adaptación al mundo Internet y a las nuevas tecnologías. La canalización y gestión de los servicios del turismo

\footnotetext{
${ }^{2}$ Directora de la Empresa Rutas de Vino de España.

3"Los enoturistas y en general el turista que visita La Rioja, utiliza cada vez más los servicios de nuestra página Web para consultar las ofertas y actos más importantes que organiza Turismo de La Rioja, nuestras últimas estadísticas internas nos dicen que un 68\% utilizan el medio Internet antes de visitar nuestra región vitivinícola" (Trigueros, 2009).
} 
enológico, también se han visto afectados en su adaptación al medio Internet y al sistema que éste exige de comunicación.

Cervera Fantoni (2006: 214) explica que lo que Internet ha añadido a la comunicación son tres conceptos clave: interactividad, personalización y globalización.

No se ha de olvidar que para conseguir un contacto eficaz y directo con futuros enoturistas o turistas enológicos es imprescindible diseñar y contar con una buena Web Site (Sitio Web).

Siguiendo las indicaciones de Cervera Fantoni (2006: 215-216), la Web corporativa debe ser atractiva y con personalidad, constituyendo un fantástico canal de retroalimentación. Este medio de comunicación permite "mimar" al usuario, acompañarle y guiarle; tratarle con el lenguaje apropiado en cada situación y todo ello sin que intervengan elementos externos de distracción.

La home page (primera pantalla y punto de acceso de Internet) debe ser, desde un punto de vista visual, atractiva y funcional; donde los elementos que la componen estén dispuestos de forma sencilla, clara y organizada. La mentalidad del usuario debe percibir que su entrada en el mundo virtual de la empresa vitivinícola se hace de forma natural, sin brusquedades (Cervera Fantoni, 2006).

El navegante debe aprender a orientarse con facilidad y acceder a la información de forma rápida 4 . La velocidad de descarga de una página Web debe ser, ante todo, rápida.

Es también muy importante actualizar los contenidos de la Web. Tarea que debe ser organizada y ejecutada por el Director de Comunicación ${ }^{5}$ de la bodega. En ocasiones, si la bodega careciera de esta figura, es una empresa externa de comunicación la que se encarga de actualizar los contenidos on-line, al igual que el resto de las acciones de comunicación.

En este aspecto, la empresa Ewin Enoturismo ha creado el primer software para la gestión integral de un centro de enoturismo, de modo que facilita las conexiones y relaciones de las empresas enoturísticas con sus diversos públicos. A continuación puede verse la transformación de los cuatro elementos tradicionales del Marketing

${ }^{4}$ La comunicación en red plantea una narrativa no lineal e incorpora de modo efectivo la respuesta del sistema o de otros usuarios en tiempo real. El navegante debe disponer de un enlace en todas las páginas (siempre en el mismo sitio y con el mismo diseño) para poder volver tanto a la presentación inicial (home-page) como para retroceder y/o avanzar en una dirección concreta (Burgos y León, 2001: 159).

${ }^{5}$ El DirCom deberá mantener al día toda la información relativa a los servicios y productos que ofrece la bodega, cuidar los aspectos de branding de la compañía, así como el desarrollo de novedades y nuevas aplicaciones para que los visitantes puedan consultarlas. Deberá también desarrollar las presentaciones corporativas que utilizarán miembros de la bodega así como la alta dirección de la bodega (Santesmases Mestre, 2004: 793-797). 
Mix: Producto, Promoción Precio y Distribución en la adaptación al sistema digital. De este modo, ahora el llamado e-Marketing Mix (adaptado a Internet) se compone ahora de: Cliente, Comunicación, Coste psicológico y Conveniencia (Holloway, 1995a: 234).

Tabla I. Los elementos del Marketing Mix aplicados en el medio Internet

\begin{tabular}{|c|c|}
\hline 4 Ps.- Marketing Mix & 4 Cs.- e-Marketing Mix \\
\hline Producto: vender lo que se produce. & Cliente: producir lo que se vende. \\
\hline $\begin{array}{l}\text { Promoción: publicidad masiva, intensiva } \\
\text { y unilateral. }\end{array}$ & Comunicación: feedback. \\
\hline $\begin{array}{l}\text { Precio: precio directo de acuerdo con } \\
\text { estudios y en relación con la competencia. }\end{array}$ & $\begin{array}{l}\text { Coste psicológico: el resultado de la } \\
\text { percepción que los clientes tienen debido } \\
\text { al coste adicional que ellos atribuyen al } \\
\text { producto. }\end{array}$ \\
\hline Distribución: lugar físico de compra. & $\begin{array}{l}\text { Conveniencia: forma más rápida de llegar } \\
\text { al cliente a través de las nuevas } \\
\text { tecnologías. }\end{array}$ \\
\hline
\end{tabular}

El marketing en Internet, el llamado e-marketing, reduce las distancias entre los mercados, potenciando así su internacionalización. Las empresas se encuentran obligadas no sólo a mirar el mercado local o nacional para su expansión, sino también a prestar atención a mercados fuera de sus fronteras (Sánchez, 2001a: 23).

Como resalta Sánchez (2001b: 78-79) en Internet, dentro del sector servicios, en concreto en el sector del turismo del vino y en el turismo en general, el hecho de poder trabajar con flujos de información y no con stocks, como en el mercado físico, resulta ventajoso por las siguientes características:

- Rapidez en tratar, obtener y consultar la información. Por lo tanto, mayor productividad.

- Fiabilidad a la hora de manejar gran cantidad de información, al contrario que con los sistemas manuales.

- Acceso directo a los hogares y al público objetivo. 
- Segmentación del mercado y de forma más precisa gracias a bases de datos con variada información sobre los públicos.

Un medio de comunicación como Internet es capaz de cambiar la naturaleza de un producto personalizándolo hacia las necesidades de cada cliente. Se realiza de manera automática recopilando la información precisa sobre el perfil de cada cliente, permitiendo a éste que configure el producto que más le interesa (Mayordomo, 2002e: 65).

Gracias a Internet se puede promocionar más características y atributos de una Comunidad Autónoma asesorando al cliente en la toma de decisiones sobre su viaje. De esta manera, Internet se ha convertido en un medio excelente e idóneo para realizar los llamados viajes a la carta.

En cualquier proyecto comunicativo existe la necesidad de marcar una estrategia de gestión. Mayordomo (2002f: 37) indica varias razones para establecer una estrategia de comercio electrónico para unos objetivos enoturísticos:

- Internet supone un reto para la empresa y su dirección, ya que como una tecnología supone una oportunidad pero también un riesgo. Por esto, la dirección de una empresa precisa de una estrategia bien definida para utilizar Internet en su negocio.

- Existencia de cambios constantes. Debido a que el mercado cambia rápidamente se exige una reacción acorde a esos cambios. Si no se dispusiera de una estrategia bien definida las decisiones tomadas en un momento crítico no estarían alineadas con los objetivos predefinidos y supondrían una pérdida de competitividad.

- La organización de la empresa se ve afectada por Internet ya que supone un cambio en la cultura y en la organización de la empresa. El proceso de cambio debe estar planificado y en línea con la estrategia de negocio.

El Marketing virtual se dirige a mantener y fidelizar al cliente mientras que el Marketing más tradicional busca la captación del consumidor. Esta diferenciación es muy importante (Alet, 1996: 18).

Este factor es de vital importancia para las bodegas que comienzan a crear sus Departamentos de Comunicación y Marketing, ya que deben contar con bases de datos actualizadas para crear y mantener todo tipo de públicos: proveedores, clientes finales, intermediarios y periodistas.

Como explica Altés (1993: 115), cuando se estructura un producto turístico se deben tener en cuenta tres niveles:

- El núcleo del producto, que es el servicio principal que fue diseñado para satisfacer las necesidades del target. En el caso de las regiones vitivinícolas, el núcleo del producto son todas aquellas actividades que giran en torno a la cultura del vino, que se han explicado en actividades de enoturismo. 
- El producto tangible, corresponde a aquello que el cliente recibirá por el precio pagado. En el caso de la Denominación de Origen Calificada Rioja y de la D.O. Ribera del Duero, el producto tangible es el vino, cuya venta está disponible a través de la página Web del Consejo Regulador. Si se hace referencia a las páginas de turismo, el producto tangible pasa a un segundo plano ya que la oferta turística es un intangible.

- El valor añadido, es todo lo que puede completar al producto tangible y así, hacerlo más interesante y atractivo para el público objetivo. Significa una oportunidad para diferenciarse de los competidores. Este valor posee una característica que individualiza al producto en la mente de los consumidores, ya que el valor añadido condiciona la actitud frente al producto turístico.

La Rioja por ejemplo no vende vino, vende cultura del vino, así como todas las experiencias que se pueden vivir en la "tierra del vino". Sin embargo, por otro lado Castilla y León potencian su naturaleza y la calidad de vida que se puede disfrutar al hospedarse en cualquiera de las nueve provincias de la Comunidad Autónoma.

Por lo tanto, se pone de manifiesto claramente en esta última valoración del libro de Altés que la comunidad de La Rioja se posiciona fundamentalmente en cultura del vino y en cambio, Castilla y León se identifican con naturaleza y calidad en el turismo de descanso.

\section{METODOLOGÍA}

Para conocer cuáles son las principales diferencias entre los planes de comunicación, objetivos y acciones en Internet, entre la D.O. Ribera del Duero y D.O.C. Rioja, se ha procedido a un análisis comparativo y descriptivo de varias páginas Web Institucionales de ambas comunidades autónomas.

Se han tomado como ejemplo la página Web de los Consejos Reguladores de las Denominaciones de Origen y de las Consejerías de Turismo de cada región.

Así, se podrán conocer las acciones que realiza Turismo de La Rioja y qué no hace Turismo de Castilla y León o por el contrario, que está desarrollando Turismo de Castilla y León y, qué no ha considerado importante la comunidad de La Rioja.

Es importante este conocimiento, ya que de esta forma se podrá evaluar la viabilidad de alguna de las acciones que obteniendo resultados positivos, pueden ser aplicables en una región $u$ otra dependiendo de su geografía, historia, filosofía, cultura, infraestructuras, gobierno y población.

Se estudia, por tanto, la comunicación y gestión sobre actividades de enoturismo que se desarrollan en Internet y que son llevadas a cabo por la Consejería de Turismo de La Rioja y de Castilla y León. De esta forma, se procederá a la contemplación de las diferencias fundamentales entre ambas comunidades en aspectos de posicionamiento del enoturismo en cada región y, de la importancia que otorgan éstas a este fenómeno como destino turístico. 
Con este análisis, también se podrá comprobar cómo funciona cada Comunidad Autónoma en la elaboración de los Planes de Comunicación ${ }^{6}$ y qué relación se establece entre la Empresa o Institución (en este caso las Consejerías de Turismo de La Rioja y la de Castilla y León) con sus públicos. Se entiende que la empresa siempre intenta transmitir su Identidad Corporativa a su target group ${ }^{7}$ con el objetivo final de generar una imagen favorable de su empresa, sus productos y servicios. En este caso, entre Institución, bodega o empresa vitivinícola hacia sus diferentes públicos.

\subsection{Cuestionario para realizar análisis comparativo de las Páginas Web de Castilla y León y La Rioja (año 2011)}

Para realizar un análisis sobre las principales páginas Web que promocionan los servicios y los productos turísticos de la comunidad de Castilla y León y La Rioja, se generó un cuestionario ${ }^{8}$ que comparara el diseño, el contenido y la interacción con el usuario principalmente de dichas páginas Web.

Para ello, se sometieron a estudio las páginas Web de Turismo de Castilla y León y La Rioja, además de las páginas Web de los Consejos Reguladores de las Denominaciones de ambas comunidades.

\subsection{Planteamiento, Diseño y Objetivos planteados en las preguntas del Cuestionario}

El cuestionario tiene dos partes estructuradas con un total de diez preguntas. La primera de ellas, comienza con preguntas abiertas sobre la comparativa entre la página Web de Turismo de las dos regiones vistas. La segunda parte, establece también una comparativa, pero en este caso entre las páginas Web de los Consejos Reguladores de Ribera del Duero y Rioja. En total diez preguntas con ocho preguntas abiertas y dos cuestiones que incluyen la escala de tipo Likert.

Las únicas preguntas cerradas se refieren a las cuestiones de tipo sociodemográfico. Éstas se incluyen al principio del cuestionario y no van enumeradas.

Las preguntas $\mathrm{N}^{\circ} 1, \mathrm{~N}^{\circ} 2$ y $\mathrm{N}^{\circ} 3$ son abiertas, al igual que la $\mathrm{N}^{\circ} 6, \mathrm{~N}^{\circ} 7$ y $\mathrm{N}^{\circ} 8$ de la segunda parte. Todas ellas buscan obtener información sobre qué página Web es más entretenida para el usuario, cuál más interactiva y en definitiva, las razones que han justificado la preferencia de una y no de otra.

Las cuestiones $\mathrm{N}^{0} 5$ y $\mathrm{N}^{0} 10$, valoran la imagen de las páginas comparadas. De este modo, se puede conocer cuál es el posicionamiento, la ventaja competitiva y la imagen

\footnotetext{
${ }^{6}$ Estrategias y acciones que contemplan en sus decisiones de comunicación hacia sus públicos.

7Según Sainz de Vicuña (1999a: 87), define al Target Group como el público objetivo al que se dirigen los esfuerzos de comunicación, es decir, los públicos a los que se quiere llegar para ofrecer unos productos y servicios. Para ello, hay que segmentar en diferentes grupos a una gran masa de personas para diseccionar de forma eficiente el target que interesa para alcanzar los objetivos de marketing.

${ }^{8}$ Cuestionario estructurado y entregado de forma física al encuestado. La selección de la muestra también fue por cuotas.
} 
de las páginas Web de Castilla y León y La Rioja. Por lo tanto, se podrá obtener una comparativa clara sobre qué página Web está mejor estructurada. Los resultados serán de gran interés, ya que se podrán hacer propuestas de futuras modificaciones en cada uno de los portales electrónicos.

Las preguntas $\mathrm{N}^{\circ} 4$ y $\mathrm{N}^{\circ} 9$ incluyen la escala de tipo Likert. Se somete al análisis el fácil acceso a la página, cómo es la navegación a través de la misma, el dinamismo, la personalización de la página, la oferta turística, cómo es la lectura y su contenido, se evalúa también si las imágenes son atractivas. Con puntuaciones del 1 (menor valor) al 5 (mayor valor), el encuestado podrá ponderar cada una de las variables establecidas en la pregunta. Con este tipo de preguntas, se podrá conocer qué página Web es la más valorada y la mejor puntuada.

\subsection{Distribución del Cuestionario}

El Cuestionario se distribuyó en mayo de 2011 en la Universidad Valladolid. Por el fácil acceso a las aulas de la Facultad de Ciencias de la Información, se obtuvo una muestra de 50 estudiantes de último curso de Publicidad y RR.PP. El criterio también fue responsabilidad del encuestador, por tanto se trata de una selección por cuotas.

La realización del cuestionario tuvo lugar en una de las asignaturas de la titulación. Se escogió la asignatura de Comunicación Corporativa en Internet porque era la más adecuada de acuerdo a los objetivos plateados en el cuestionario. Además, al impartir la docencia en el laboratorio, se disponía de ordenadores conectados a la red.

Primeramente, se explicó cuáles eran los objetivos del cuestionario y se informó a los estudiantes que disponían de 90 minutos para navegar por cada una de las páginas $\mathrm{Web}^{9}$ sometidas al posterior análisis comparativo.

Transcurridos los 90 minutos, se apagaron los ordenadores y se entregaron los cuestionarios. Apagados los ordenadores se podía valorar el recuerdo de los estudiantes y efecto memoria de cada uno de los estudiantes sobre las páginas web comparadas. Se dispuso de 20 minutos para contestar a los cuestionarios.

Finalmente se recogieron los cuestionarios y se procedió a la lectura y al posterior análisis en el verano de 2011. Este cuestionario incluía en su mayoría un mayor número de preguntas abiertas para proceder a un análisis cualitativo.

Al tratarse de una muestra pequeña de 50 estudiantes, se podía analizar mejor cada una de las preguntas abiertas.

\footnotetext{
9Se indicó que se compararan primero las páginas Web de Turismo y después las páginas Web de los Consejos Reguladores. Se estableció un orden de análisis y lectura que correspondía con la estructura de las preguntas del cuestionario.
} 


\section{ANÁLISIS Y DISCUSIÓN}

\subsection{Páginas Web de Turismo (2011)}

A través del análisis de las páginas Web tomadas como referencia de estudio y, de la realización del cuestionario a la muestra de 50 estudiantes $^{10}$ de la Universidad de Valladolid, se han llegado a los siguientes resultados y sugerencias para futuros y posibles cambios:

Las tres primeras preguntas del cuestionario intentan saber qué página de turismo ha gustado más, cuál es más entretenida y cuál de las dos mantiene una interactividad más alta con el usuario. Tras los resultados a estas primeras preguntas se han sugerido las siguientes acciones para la renovación de la página Web de Turismo de Castilla y León:

- Es necesaria la creación de un Mapa Web para navegar de un modo más sencillo por la página, ya que de esta forma los usuarios no se perderían y sabrían en todo momento cuál es su ubicación dentro de la Web.

- Sería conveniente colocar un enlace para retroceder al inicio cuando se navega por la página y para facilitar de este modo, el retroceso a la home page (página principal).

- Los menús deberían ser desplegables para conocer dentro de ellos las ofertas de turismo que aparecen en el menú izquierdo.

- Hay que destacar de un modo más llamativo la oferta turística en el centro de la página, sin que la estructura de la misma obligue a descender el cursor para conocerlo todo. Quizá en la parte central se abuse de informaciones y sería necesario destacar sólo lo más importante de un modo más dinámico para atraer a los usuarios de la página. Sería conveniente poner en la parte superior varios links que lleven de forma directa a las novedades de la página, así como accesos directos a los buscadores de una manera más llamativa.

- Realizar una clasificación más correcta que englobe los distintos tipos de turismo que se pueden encontrar en la comunidad.

- A pesar de que la distribución de la amplia oferta turística de Castilla y León es compleja, deberían existir vínculos entre unas secciones y otras, ya que muchas de las secciones que aparecen en el menú izquierdo están relacionadas.

- Deberían existir enlaces externos a otras páginas que sustenten la información que se ofrece en esta Web y que apoyen y favorezcan la imagen de marca que pretende posicionar Castilla y León en el mercado. De esta forma, se ofrece una sensación de unidad entre todos los organismos y empresas que contribuyen a mejorar la imagen de la comunidad.

- El tipo y el color de la letra resultan monótonos, por lo que sería conveniente cambiarlo por uno que resulte más llamativo y atractivo. Además, sería necesario

\footnotetext{
10Se recuerda que el cuestionario se llevó a cabo en la Universidad de Valladolid en mayo de 2011 a una muestra de estudiantes de publicidad después de haber visitado cada una de las páginas Web.
} 
destacar en otro tipo de letra y en color lo más importante, ya sean direcciones de interés turístico, teléfonos de contacto o los enlaces más destacados.

- Es necesario introducir más imágenes con más dinamismo, que ofrezcan mejor calidad y más atractivo a la vista del usuario; ya que una imagen resulta un reclamo más eficaz que el exceso de información a la hora de fidelizar al usuario.

- Potenciar la interactividad con el usuario para que se sienta parte integrante de la comunidad.

- Facilitar información personalizada a cada tipo de público que visita la Web, proporcionándole herramientas como foros, preguntas frecuentes, correo electrónico, teléfono de atención y buzón de sugerencias.

- Personalizar cada frase, haciendo al cliente único.

- Crear un espacio destinado a clientes habituales o amigos de la comunidad, donde éstos cuenten sus experiencias y reciban ofertas personalizadas.

- Reducir la cantidad de información para que la que aparezca sea más directa y no provoque cansancio en el consumidor.

- Unificar toda la oferta turística para crear una ventaja competitiva que incite al consumidor a visitar tanto virtual como físicamente la comunidad.

- Desarrollar características de entretenimiento como vídeos interactivos o área de descargas y juegos, por ejemplo, puzzles de los monumentos más destacados, con el objetivo de fidelizar a los usuarios de la página.

- Actualización, crear para ello un espacio con publicidad e información acerca de las fiestas más destacadas de la región en cada época del año para dar sensación de inmediatez.

Tras analizar las Web de turismo de ambas comunidades autónomas se destaca que Castilla y León despierta de un largo letargo en el que estaba sumida. Las acciones comunicativas están cambiando y se ha pasado de la mera información a un plan de gestión y comunicación muy sugerente como indica su lema principal: "Castilla y León es vida".

En efecto, Castilla y León no es una tierra árida y sin vida, sino que su oferta turística es un signo de vitalidad y dinamismo. Ya no aporta información sin más, sino que también facilita al usuario un intangible ${ }^{11}$, una experiencia inolvidable llena de vida.

Además, las páginas Web sirven para acercar el producto al usuario, personalizar su oferta y hacer creer al cliente que es único, a través de la Comunicación One to One ${ }^{12}$.

La Rioja ha sabido combinar este último aspecto, es decir, la información y contenidos con la interacción entre la página y el usuario, primando al cliente sobre la Institución que está detrás de dicha página. Esto se logra tras una planificación exhaustiva del eje comunicativo que pretenden dar a conocer y por el que el público objetivo les recuerde. En este aspecto Castilla y León debiera cuidar más la interactividad con el usuario.

\footnotetext{
${ }^{11}$ Valores emocionales que se añaden a la marca o producto.

12 Comunicación individualizada.
} 
Un mayor porcentaje de encuestados manifiestan que les ha gustado más la Web de Turismo de La Rioja que la de Castilla y León (un 72\%); destacando la aplicación de las imágenes, la interactividad con el usuario (67\%) y el dinamismo de la estructura de la Web. Muchos opinan (un 72\%) que es más entretenida la página Web de Turismo de La Rioja que la página Web de Turismo de Castilla y León.

La siguiente pregunta número cuatro valora varias características esenciales de la página Web de Turismo de Castilla y León y La Rioja, puntuadas del 1 al 5. Se detallan a continuación:

\begin{tabular}{|l|l|l|l|l|l|l|l|l|}
\hline & $\begin{array}{l}\text { Fácil } \\
\text { acceso a } \\
\text { la página }\end{array}$ & $\begin{array}{l}\text { Navegación } \\
\text { sencilla }\end{array}$ & $\begin{array}{l}\text { Dinamismo } \\
\text { y atractivo }\end{array}$ & $\begin{array}{l}\text { Interactividad } \\
\text { usuario }\end{array}$ & $\begin{array}{l}\text { Personalización } \\
\text { de la página }\end{array}$ & $\begin{array}{l}\text { Imágenes } \\
\text { atractivas } \\
\text { Ofurtástica } \\
\text { definida }\end{array}$ & $\begin{array}{l}\text { Lectura } \\
\text { fluida } \\
\text { calidad }\end{array}$ \\
\hline $\mathbf{1}$ & $0,0 \%$ & $0,0 \%$ & $16,0 \%$ & $0,0 \%$ & $12,0 \%$ & $4,0 \%$ & $0,0 \%$ & $0,0 \%$ \\
\hline 2 & $10,0 \%$ & $0,0 \%$ & $20,0 \%$ & $22,0 \%$ & $18,0 \%$ & $0,0 \%$ & $6,0 \%$ & $8,0 \%$ \\
\hline 3 & $18,0 \%$ & $18,0 \%$ & $40,0 \%$ & $14,0 \%$ & $32,0 \%$ & $76,0 \%$ & $18,0 \%$ & $18,0 \%$ \\
\hline 4 & $\mathbf{6 2 , 0} \%$ & $42,0 \%$ & $24,0 \%$ & $20,0 \%$ & $6,0 \%$ & $20,0 \%$ & $22,0 \%$ & $26,0 \%$ \\
\hline 5 & $10,0 \%$ & $40,0 \%$ & $0,0 \%$ & $\mathbf{4 4 , 0} \%$ & $\mathbf{3 2 , 0} \%$ & $0,0 \%$ & $\mathbf{5 4 , 0} \%$ & $\mathbf{4 8 , 0} \%$ \\
\hline
\end{tabular}

Como se observa a través de los datos, un porcentaje muy alto (el 54\%) valora con la máxima puntuación la lectura fluida de la página Web analizada (Castilla y León). Un $44 \%$ valora la interactividad con un valor muy alto de 5 . El $48 \%$ considera que las imágenes de la página Web de Turismo de Castilla y León son de calidad y atractivas (también se valora con una cifra muy alta de 5). Un porcentaje alto (con la segunda valoración más alta de 4), un $62 \%$ destaca la facilidad de acceso a la página. En la siguiente figura 1, se detalla de forma visual lo comentado anteriormente. 
Figura 1. Valoración página Web de Turismo de Castilla y León

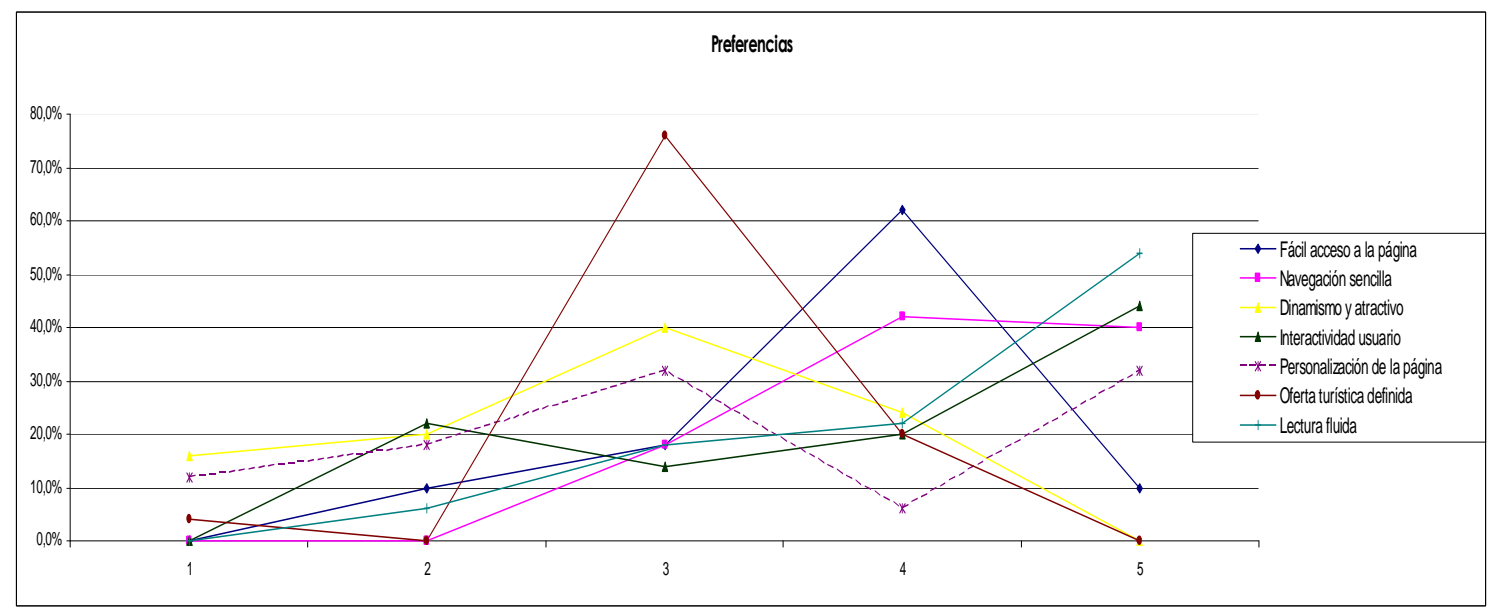

A continuación se detalla la tabla de la valoración de la página Web de Turismo de La Rioja.

Tabla III. Valoración página Web de Turismo de La Rioja

\begin{tabular}{|c|c|c|c|c|c|c|c|c|}
\hline & $\begin{array}{l}\text { Fácil } \\
\text { acceso } \\
a \quad \text { la } \\
\text { página }\end{array}$ & $\begin{array}{l}\text { Navegación } \\
\text { sencilla }\end{array}$ & $\begin{array}{l}\text { Dinamismo } \\
\text { y atractivo }\end{array}$ & $\begin{array}{l}\text { Interactividad } \\
\text { usuario }\end{array}$ & $\begin{array}{l}\text { Personalización } \\
\text { de la página }\end{array}$ & $\begin{array}{l}\text { Oferta } \\
\text { turística } \\
\text { definida }\end{array}$ & $\begin{array}{l}\text { Lectura } \\
\text { fluida }\end{array}$ & \begin{tabular}{|l|} 
Imágenes \\
atractivas \\
$y \quad$ de \\
calidad
\end{tabular} \\
\hline 1 & $0,0 \%$ & $0,0 \%$ & $4,0 \%$ & $0,0 \%$ & $0,0 \%$ & $0,0 \%$ & $0,0 \%$ & $0,0 \%$ \\
\hline 2 & $0,0 \%$ & $16,0 \%$ & $4,0 \%$ & $0,0 \%$ & $18,0 \%$ & $8,0 \%$ & $0,0 \%$ & $0,0 \%$ \\
\hline 3 & $14,0 \%$ & $38,0 \%$ & $22,0 \%$ & $10,0 \%$ & $26,0 \%$ & $32,0 \%$ & $14,0 \%$ & $28,0 \%$ \\
\hline 4 & $24,0 \%$ & $46,0 \%$ & $6,0 \%$ & $14,0 \%$ & $36,0 \%$ & $20,0 \%$ & $22,0 \%$ & $12,0 \%$ \\
\hline 5 & $62,0 \%$ & $0,0 \%$ & $64,0 \%$ & $76,0 \%$ & $20,0 \%$ & $40,0 \%$ & $64,0 \%$ & $60,0 \%$ \\
\hline
\end{tabular}

En este caso, un porcentaje muy alto del 64\% valora con la máxima puntuación de 5 la lectura fluida de la Web y el dinamismo y atractivo de ésta. Un 62\% también valora el fácil acceso a la página y el $60 \%$ la calidad e las imágenes y su atractivo.

El valor más destacado es que el $76 \%$ de los encuestados detallan de forma sobresaliente la interactividad que mantiene la Web con el usuario (valoración máxima de 5).

En la siguiente figura 2 se detallan los datos comentados. 
Figura 2. Valoración página Web de Turismo La Rioja

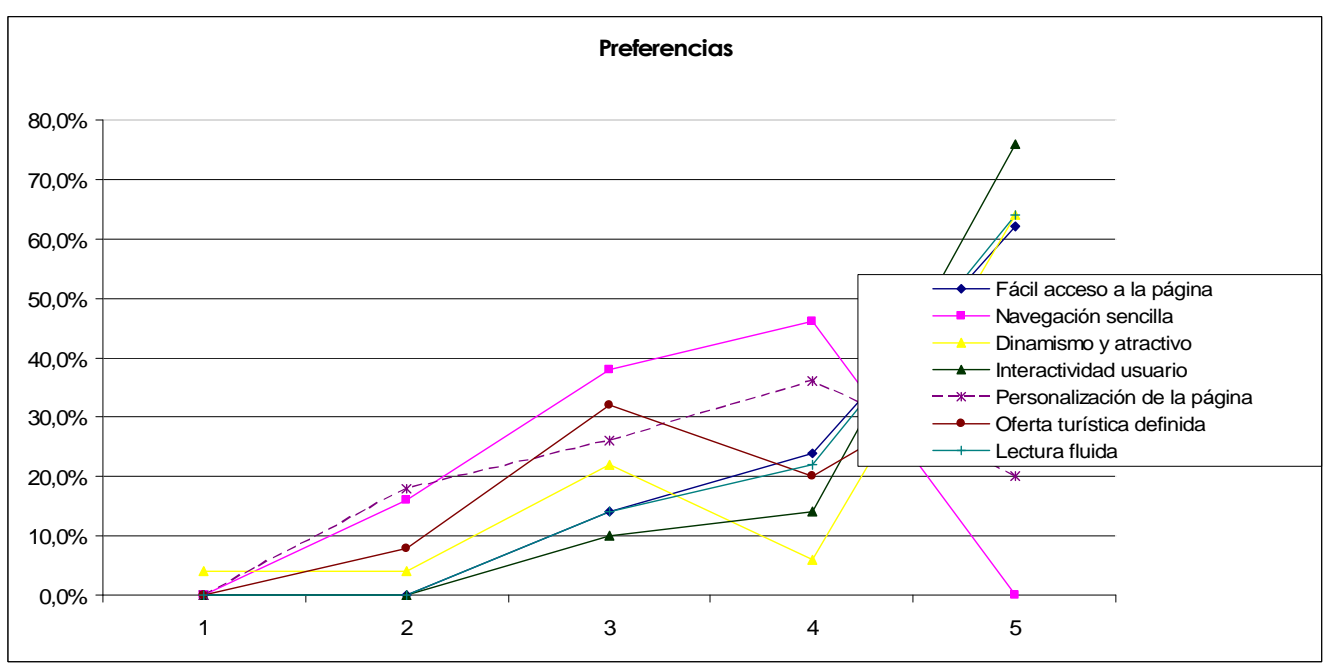

Habiendo visto todo esto, se puede concluir y resumir gracias a la pregunta número cinco del cuestionario que la imagen de la Web de Turismo de La Rioja está por encima de la Web de Turismo de Castilla y León. Esta última consigue tener un posicionamiento y ventaja competitiva poco clara y definida; además de percibirse con un mensaje difuso y lleno de informaciones.

Las siguientes preguntas seis, siete y ocho cuestionan las páginas Web de la D.O.C. La Rioja y la Web de la D.O. Ribera del Duero.

En este aspecto, cabe destacar que existe un equilibrio en el resultado de la valoración de ambas páginas Web. El 56\% admite que le ha gustado más la página Web de la D.O. Ribera del Duero; quizá sea por el sonido incorporado de la naturaleza y las sensaciones a las que alude con el texto y eslogan. Un 58\% mantiene la afirmación de que es más interactiva con el usuario y un $66 \%$ que es más entretenida que la Web de la D.O.C. La Rioja.

De este modo, se resume que en este caso la Web de la D.O. Ribera del Duero sale mejor valorada que su Web de Turismo de Castilla y León. En cambio, La Web de Turismo de La Rioja consigue ser mejor que su página Web de la D.O.C.

La siguiente cuestión número nueve, somete a valoración a través de varias escalas del 1 al 5 varias características de la página Web. Las siguientes tablas y figuras muestran estos resultados de las valoraciones de las páginas Web de las Denominaciones de Origen de Ribera del Duero y La Rioja. 
3.2. Web de las Denominaciones de Origen de Ribera del Duero y La Rioja (2011)

Tabla IV. Valoración página Web de la D.O.C. La Rioja

\begin{tabular}{|c|c|c|c|c|c|c|c|c|}
\hline & \begin{tabular}{|l} 
Fácil \\
acceso \\
$a \quad l a$ \\
página
\end{tabular} & $\begin{array}{l}\text { Navegación } \\
\text { sencilla }\end{array}$ & $\begin{array}{l}\text { Dinamismo } \\
\text { y atractivo }\end{array}$ & $\begin{array}{l}\text { Interactividad } \\
\text { usuario }\end{array}$ & $\begin{array}{l}\text { Personalización } \\
\text { de la página }\end{array}$ & $\begin{array}{l}\text { Oferta } \\
\text { turística } \\
\text { definida }\end{array}$ & $\begin{array}{l}\text { Lectura } \\
\text { fluida }\end{array}$ & $\begin{array}{l}\text { Imágenes } \\
\text { atractivas } \\
y \quad d e \\
\text { calidad }\end{array}$ \\
\hline 1 & $0,0 \%$ & $0,0 \%$ & $0,0 \%$ & $58,0 \%$ & $12,0 \%$ & $0,0 \%$ & $0,0 \%$ & $0,0 \%$ \\
\hline 2 & $24,0 \%$ & $4,0 \%$ & $38,0 \%$ & $24,0 \%$ & $24,0 \%$ & $0,0 \%$ & $0,0 \%$ & $22,0 \%$ \\
\hline 3 & $38,0 \%$ & $0,0 \%$ & $46,0 \%$ & $8,0 \%$ & $40,0 \%$ & $8,0 \%$ & $16,0 \%$ & $22,0 \%$ \\
\hline 4 & $20,0 \%$ & $52,0 \%$ & $0,0 \%$ & $10,0 \%$ & $24,0 \%$ & $34,0 \%$ & $42,0 \%$ & $30,0 \%$ \\
\hline 5 & $18,0 \%$ & $44,0 \%$ & $16,0 \%$ & $0,0 \%$ & $0,0 \%$ & $58,0 \%$ & $42,0 \%$ & $26,0 \%$ \\
\hline
\end{tabular}

Un $58 \%$ valora con la máxima puntuación la oferta turística definida y un $42 \%$ la lectura fluida. En cambio, un 58\% no destaca la interactividad mantenida de esta Web con el usuario. Un $44 \%$ valora con una puntuación alta de 5 la navegación sencilla por la Web. La figura 3 muestra los resultados de forma gráfica.

Figura 3. Valoración página Web de la D.O.C. La Rioja

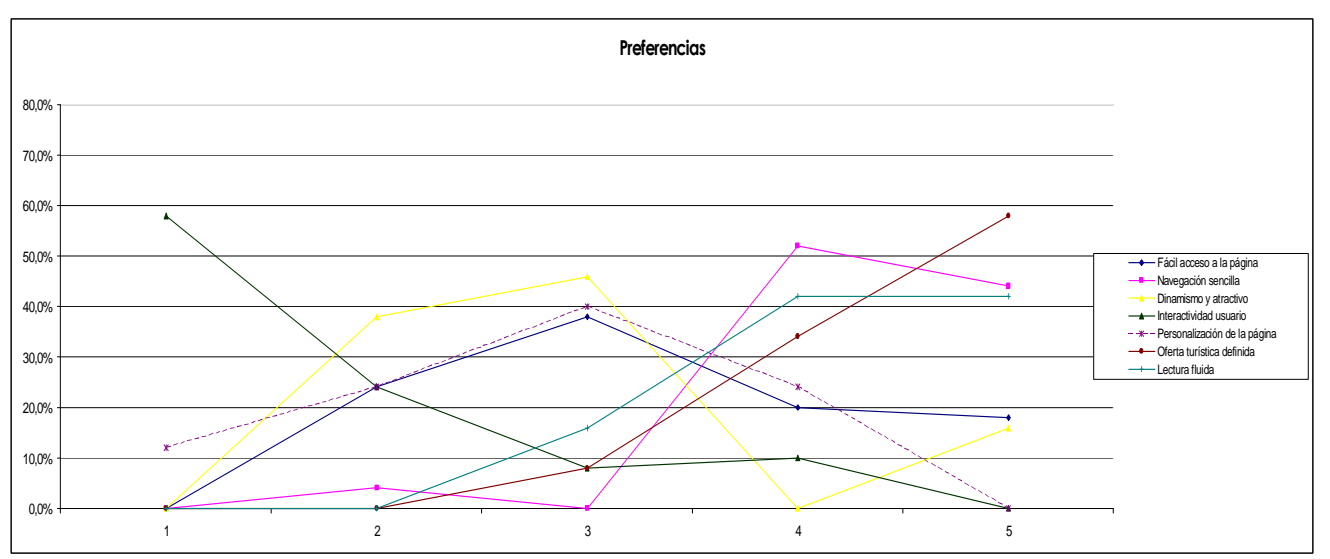

A partir de las siguientes tablas y figuras se detallan los valores obtenidos sobre la valoración de la página Web de la D.O. Ribera del Duero. 
Tabla V. Valoración página Web de la D.O. Ribera del Duero

\begin{tabular}{|l|l|l|l|l|l|l|l|l|}
\hline \multicolumn{1}{|l|}{$\begin{array}{l}\text { Fácil } \\
\text { acceso a } \\
\text { la página }\end{array}$} & $\begin{array}{l}\text { Navegación } \\
\text { sencilla }\end{array}$ & $\begin{array}{l}\text { Dinamismo } \\
\text { atractivo }\end{array}$ & $\begin{array}{l}\text { Interactividad } \\
\text { usuario }\end{array}$ & $\begin{array}{l}\text { Personalización } \\
\text { de la página }\end{array}$ & $\begin{array}{l}\text { Oferta } \\
\text { turística } \\
\text { definida }\end{array}$ & $\begin{array}{l}\text { Lecturágenes } \\
\text { fluida }\end{array}$ & $\begin{array}{l}\text { atractivas } \\
\text { de } \\
\text { calidad }\end{array}$ \\
\hline $\mathbf{1}$ & $0,0 \%$ & $0,0 \%$ & $16,0 \%$ & $0,0 \%$ & $12,0 \%$ & $4,0 \%$ & $0,0 \%$ & $0,0 \%$ \\
\hline 2 & $10,0 \%$ & $0,0 \%$ & $20,0 \%$ & $22,0 \%$ & $18,0 \%$ & $0,0 \%$ & $6,0 \%$ & $8,0 \%$ \\
\hline 3 & $18,0 \%$ & $18,0 \%$ & $40,0 \%$ & $14,0 \%$ & $32,0 \%$ & $76,0 \%$ & $18,0 \%$ & $18,0 \%$ \\
\hline 4 & $62,0 \%$ & $42,0 \%$ & $24,0 \%$ & $20,0 \%$ & $6,0 \%$ & $20,0 \%$ & $22,0 \%$ & $26,0 \%$ \\
\hline 5 & $10,0 \%$ & $40,0 \%$ & $0,0 \%$ & $44,0 \%$ & $32,0 \%$ & $0,0 \%$ & $\mathbf{5 4 , 0} 0$ & $\mathbf{4 8 , 0} \%$ \\
\hline
\end{tabular}

Como se observa en la tabla 5 , un $76 \%$ valoran la oferta turística definida con un valor medio de 3 . Un $54 \%$ de los encuestados valoran con un valor de 5 la lectura fluida de la página. Mientras un $48 \%$ también valora con un valor alto la calidad y el atractivo de las imágenes. Un $20 \%$ destaca con un valor bajo el dinamismo y el atractivo de las imágenes. La figura 4 muestra las cifras.

Figura 4. Valoración página Web de la D.O. Ribera del Duero

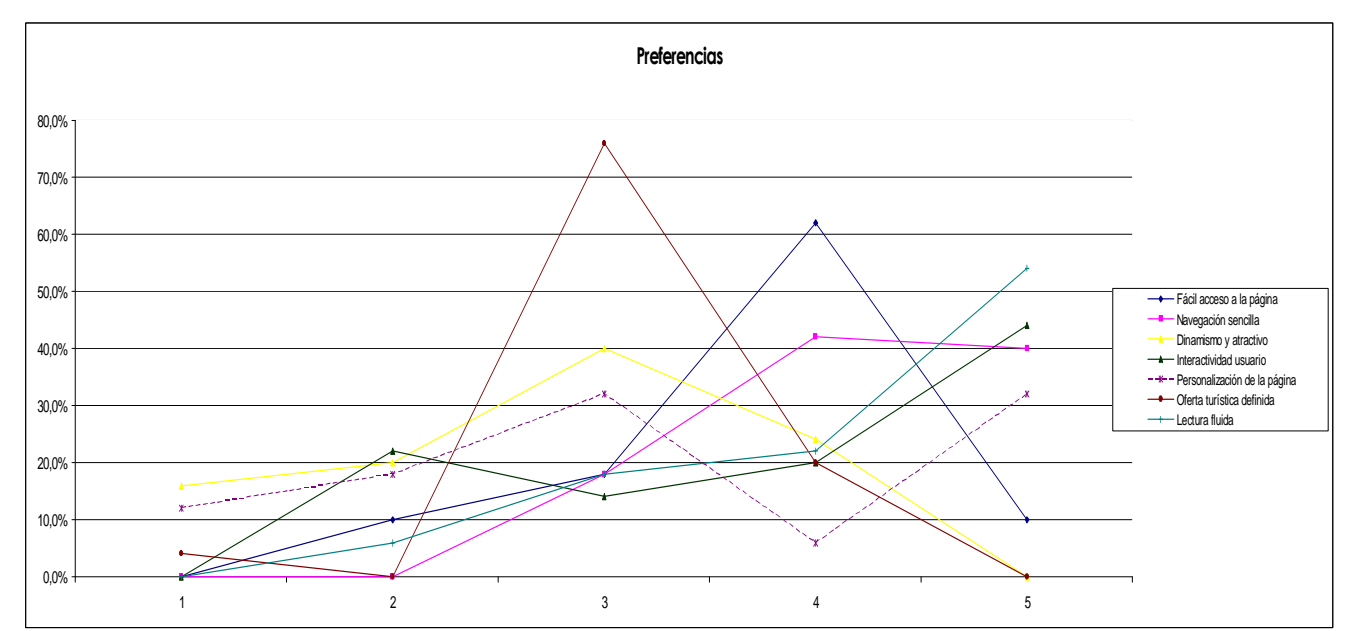

La última pregunta tiene por objetivo conocer cuál de las dos páginas Web obtiene una mejor valoración en cuanto al posicionamiento, la identificación de su ventaja competitiva y la exposición y claridad de sus mensajes. En este aspecto es la Web de la D.O. Ribera del Duero la que obtiene una mejor puntuación ya que un $67 \%$ valora de forma positiva la imagen proyectada, su posicionamiento y ventaja competitiva respecto a la D.O.C. La Rioja. 
Finalmente queda por especificar los datos sociodemográficos de los estudiantes encuestados. Como se observará los datos de edad son muy similares.

Tabla VI. Edad de los encuestados I

\begin{tabular}{|l|l|l|l|l|l|}
\hline \multicolumn{6}{|c|}{ Edad } \\
\hline Mínimo & $1^{\text {er }}$ Cuartil & Mediana & Media & $3^{\text {er }}$ Cuartil & Máximo \\
\hline 21 & 22 & 22 & 22,1 & 22 & 26 \\
\hline
\end{tabular}

Tabla VII. Edad de los encuestados II

\begin{tabular}{|c|c|c|c|}
\hline & & Edad & \\
\hline $\begin{array}{l}\text { Número de } \\
\text { Encuestas } \\
\text { Realizadas }\end{array}$ & $\begin{array}{lr}\text { Limite } & \text { Inferior } \\
\text { Intervalo } & \text { de } \\
\text { Confianza } & \text { para la } \\
\text { Media al 95\% } & \end{array}$ & Media & \begin{tabular}{lrr} 
Limite & \multicolumn{2}{r}{ Superior } \\
Intervalo & de \\
Confianza & para & la \\
Media al 95\% &
\end{tabular} \\
\hline 50 & 21,7 & 22,1 & 22,3 \\
\hline
\end{tabular}

Como se ha visto la edad media alcanzada es de 22,1 años y prácticamente coincide con la mediana que es 22. Se trata de una distribución casi simétrica. En las siguientes figuras se muestran de forma visual esta apreciación. El normal quantile plot detalla el equilibrio que existe en todas las respuestas obtenidas.

Figura 5. Diagrama de Cajas de la Edad

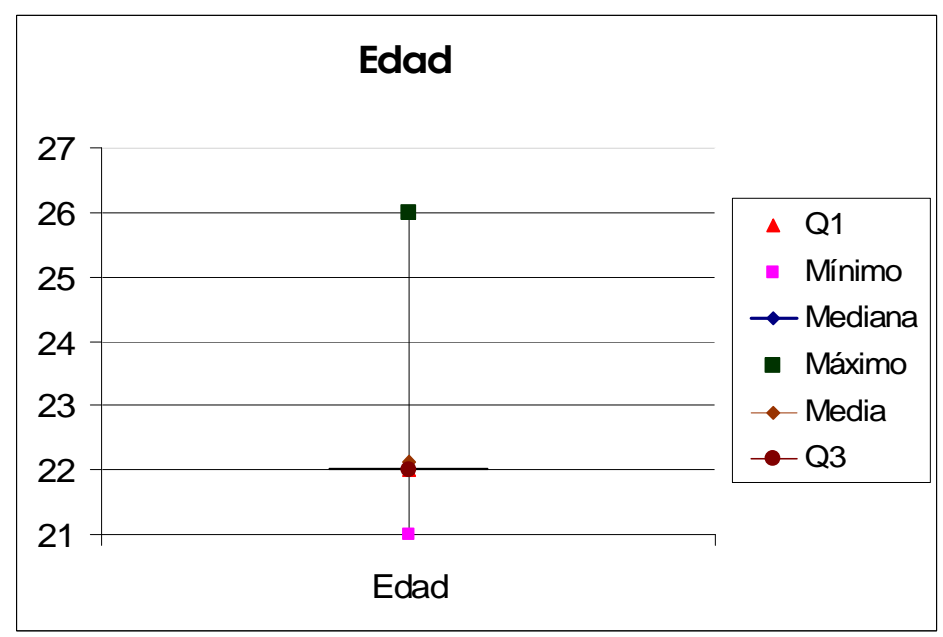


Figura 6. Normal quantile plot de la Edad

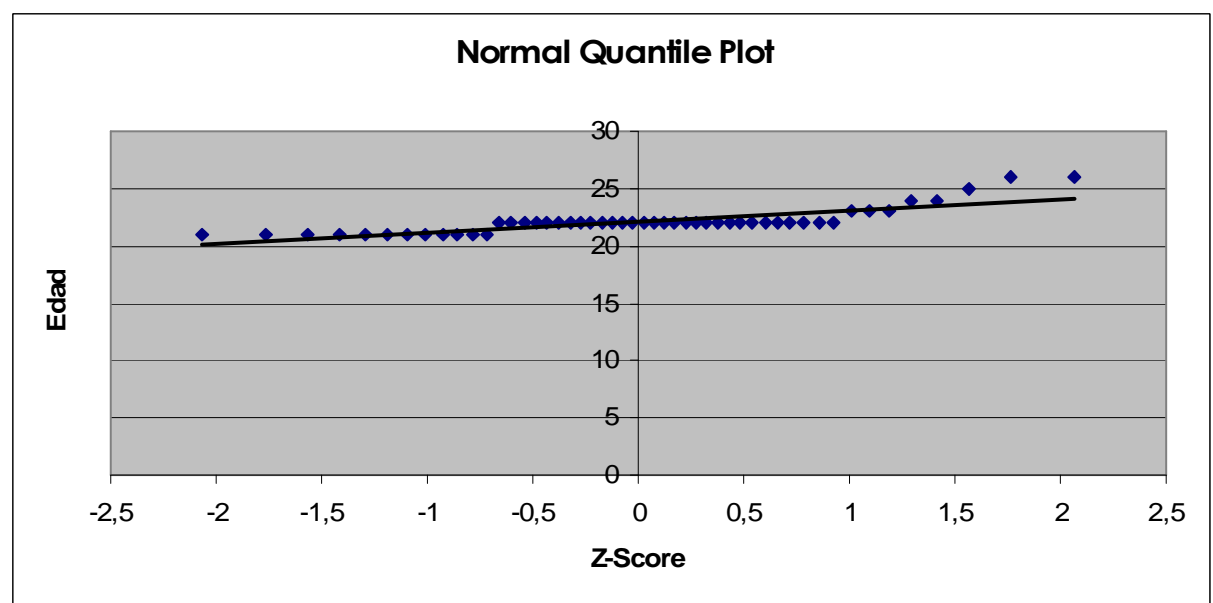

Finalmente hay que destacar que el porcentaje de mujeres encuestadas fue del 76\%, muy superior al de hombres estudiantes que tan sólo fue del $24 \%$. A pesar de la pequeña muestra el equilibrio entre hombres y mujeres encuestadas no existe.

\section{CONCLUSIONES}

Como se planteaba en un inicio en varias preguntas de investigación sobre las diferencias entre los planes de comunicación sobre enoturismo de las dos Comunidades Autónomas de Castilla y León y Rioja, existe un distinto tratamiento y enfoque del sector vitivinícola por parte de éstas a través del medio Internet.

A partir del análisis de la información sobre actividades y servicios de enoturismo a través de las páginas Web de Turismo y de los Consejos Reguladores de las dos comunidades, se ha llegado a los siguientes resultados:

Se ha comprobado que un plan de gestión y comunicación bien elaborado y llevado a cabo por todas las Instituciones que atañen al sector vitivinícola, son garantía de éxito en la promoción de un producto o servicio.

En primer lugar, se ha podido verificar que en el caso de Castilla y León las acciones realizadas tanto en los medios de comunicación como en el exterior no coinciden con lo expresado en la página Web de Turismo. El sector vitivinícola es objeto de análisis en la prensa diaria de la comunidad, sin embargo, en la página Web no destaca sobre el resto de la oferta turística. Además, en la Feria de Turismo de Interior 2011 (INTUR) celebrada en Valladolid en el mes de noviembre, el enoturismo era el eje comunicativo de la comunidad y de la provincia. En este aspecto, la información sobre dicho evento no aparecía ni en la página Web de Turismo de Castilla y León, ni en la página Web del Consejo Regulador D.O. Ribera del Duero. 
En el caso de la comunidad de La Rioja, todo gira alrededor del sector vitivinícola. Tras analizar las distintas ventajas competitivas de la región, el vino se ha convertido en el reclamo turístico, englobando a su vez toda la oferta turística de la zona. Las acciones realizadas para gestionar y promocionar la comunidad autónoma coinciden con lo especificado en su página Web de Turismo, mostrando una unidad entre lo que se pretende trasmitir y lo que se consigue finalmente comunicar. De esta manera, es más sencillo posicionar la región en la mente del consumidor, ya que La Rioja y el vino están íntimamente relacionados.

Teniendo muy presente que el objetivo de los sitios Web de los Consejos Reguladores es informar al usuario sobre lo referente al sector vitivinícola, la página oficial de la D.O. Ribera del Duero resulta más dinámica y atractiva para el visitante. Le ofrece la posibilidad de ampliar la información que éste desee como una forma de interactuar con el usuario y personalizar los contenidos. Sin embargo, la página oficial de la D.O.C. Rioja presenta un exceso de contenidos y parece estar más dirigida hacia los profesionales que a un usuario que se interese por el sector en un momento concreto.

Como se ha especificado anteriormente, la Web del Consejo Regulador D.O. Ribera del Duero es mejor en muchos aspectos que el C.R.D.O.C. Rioja. A pesar de esto, se considera que existe una falta de unidad entre la página de Turismo perteneciente a la Junta de Castilla y León y el Consejo Regulador de la D.O. Ribera del Duero; ya que ambas deberían estar vinculadas para crear un plan comunicativo y de gestión conjunto que facilite la promoción y el posicionamiento del enoturismo en la mente de los clientes.

Sainz de Vicuña explica (1999b: 34-42) que en todo Plan de Comunicación hay que tener en cuenta los siguientes tres aspectos:

Primero, una clara definición de la Identidad Corporativa, es decir, lo que es la empresa, sus objetivos corporativos y principios: su filosofía de trabajo.

La Imagen percibida actualmente; lo que el mercado percibe hoy en día de la empresa, es decir, cómo la ven los diferentes públicos externos.

La Imagen Ideal de la empresa; la imagen que se quiere transmitir a los diferentes mercados debe responder a un Plan Estratégico de Imagen, en el que deben quedar establecidos los diferentes target a los que dirigir las acciones de comunicación con una estrategia propia y específica para cada uno de ellos.

El plan de comunicación por lo tanto, debe contener tres grandes áreas si se quiere transmitir una idea clara y eficaz de modo que se consigan los objetivos de enoturismo:

La definición de los objetivos de comunicación más adecuados para transformar la imagen actual de la empresa / bodega en la imagen ideal para cada uno de los públicos. 
La definición de la estrategia de medios y de mensajes que mejor se adapten a la consecución de los objetivos previamente definidos.

La definición de un calendario de actuación y la evaluación de los costes de las acciones propuestas, así como un instrumento de control para realizar un seguimiento del plan (Sainz de Vicuña, 1999c: 110).

Todas estas tareas se organizan, planifican y dirigen desde la Dirección de Comunicación de la empresa vitivinícola o bodega, ya que es este Departamento el encargado de elaborar el plan estratégico de la imagen de la misma.

En el caso de no existir este Departamento de Comunicación o Marketing13, es el Departamento Comercial ${ }^{14}$ el encargado de realizar este tipo de acciones.

La realidad, es que la imagen influencia la decisión de visitar un lugar turístico y el consumidor la utiliza como un criterio de peso para establecer comparaciones entre diferentes alternativas. Esta imagen define el atractivo turístico a los ojos del consumidor; del mismo modo que genera la satisfacción a las necesidades y expectativas del cliente. El consumidor juzga las cosas por lo que cree que son, aunque esa imagen, buena o mala, no siempre coincide con la realidad (Middleton, 1994).

\section{REFERENCIAS}

Alet, J. (1996). Marketing Relacional. Barcelona: Gestión 2000. 1996.

Altés, C. (1993). Marketing y Turismo. Madrid: Editorial Síntesis.

Bachs, J., López Jurado, M., Llagues, M. (2002). Internet, comercio electrónico y plan de negocio. Bilbao: Ediciones Deusto.

Burgos, D., León, L. (2001). Comercio electrónico, publicidad y marketing en Internet. Madrid: McGraw - Hill.

Cervera Fantoni, A.L. (2006). Comunicación Total. Madrid: Esic.

Fleming, P. (2000). Hablemos de marketing interactivo. Madrid: Esic.

Gómez, A. (2006). Marketing relacional directo e interactivo. Madrid: Ra-Ma Editorial.

Holloway, J. C., Robinson, C. (1995). Marketing for tourism. Singapore: Longman.

\footnotetext{
${ }^{13}$ Actualmente, puede decirse que el grado de desarrollo y éxito de la mayoría de las empresas está en función de los recursos que han destinado a las actividades de marketing, y de las acciones acertadas que han emprendido gracias a la existencia de un Departamento de Marketing. Así, el marketing constituye la principal actividad de las empresas multinacionales que han alcanzado mayores crecimientos y rentabilidades (Patxot, 2003: 415).

${ }^{14}$ No debiera ser así, aunque en el mayor número de los casos de las bodegas de la D.O. Ribera del Duero, no tienen Departamentos de Comunicación o Marketing que funcionen independientemente. Tan sólo un 30\% de las 226 inscritas oficialmente en D.O. Ribera del Duero, tienen un Departamento de Comunicación (Cano Uribe, 2010).
} 
Janal, D.S. (2000). Marketing en Internet. México, D.F.: Prentice Hall.

Mayordomo, J. L. (2003). E-marketing. Barcelona: Gestión 2000.

Mazarrasa, M. (1994). Marketing y calidad total: Imagen de calidad y comunicación. Barcelona: Gestión 2000.

Middleton, V. T. C. (1994). Marketing in travel and tourism. Oxford: Butterworth-Heinemann.

Patxot, X. (2003). Marketing y Vino. Madrid: Prentice Hall.

Peppers, L., Rogers, A. (1993). Investigaciones en el mercado turístico. Madrid: Pirámide.

Pérez, A. (2000). Estrategias de Comunicación. Barcelona: Ariel.

Sainz De Vicuña Ancín, J.M. (1999). El Plan de Marketing en la Práctica. Madrid: Esic.

Sánchez Herrera, J. (2001). Plan de Marketing. Madrid: Pirámide.

Santesmases, M. (2004). Marketing: Conceptos y Estrategias. Madrid: Pirámide.

\subsection{Webgrafía y otras fuentes consultadas}

Alonso, C. (2009): "El funcionamiento de las Agencias especializadas de Enoturismo". 2 ${ }^{\mathrm{a}}$ Edición del Salón Internacional del Turismo del Vino DestinoVino 2009 (Logroño, 12, 13, 14 y 15 de abril).

Trigueros, B. (2009): "El funcionamiento de las Agencias especializadas de Enoturismo". $2^{\mathrm{a}}$ Edición del Salón Internacional del Turismo del Vino DestinoVino 2009 (Logroño, 12, 13, 14 y 15 de abril).

Encuesta realizada por email al Director de Comunicación del Consejo Regulador D.O. Ribera del Duero en el año 2010.

Sitio Web de la bodega: www.torremilanos.com. Web visitada el 2 de enero de 2011.

Sitio Web de la empresa Eniac Ewin Enoturismo:

http://www.eniac.es/nueva/pymes/ewinenoturismo.shtml . Web visitada el 10 de diciembre de 2011.

\section{Mónica Matellanes-Lazo.}

Doctora Licenciada (2001) en Publicidad y RR.PP. por la Universidad Complutense de Madrid y Doctora (2009) por la Universidad de Valladolid en Comunicación sobre del Enoturismo. Ha trabajado en Comunicación y Marketing dentro del área vitivinícola y actualmente es profesora adjunta en Comunicación y Marketing en la Universidad Europea Miguel de Cervantes de Valladolid. Varias veces profesor erasmus y congresista en Universidades extranjeras de Portugal (Lisboa, Ponte de Lima) y en 
Reino Unido (Aberystwyth). Autor de varios artículos de investigación en el área de Comunicación y la Web 2.0, últimas apariciones en Sphera, Egitania, Vivat Academia, Razón y Palabra. 